\title{
Variabilidade genética em acessos de caupi analisada por meio de marcadores RAPD
}

\author{
Gustavo Ribeiro Xavier ${ }^{(1)}$, Lindete Miria Vieira Martins ${ }^{(2)}$, Norma Gouvêa Rumjanek ${ }^{(1)}$ \\ e Francisco Rodrigues Freire Filho ${ }^{(3)}$
}

\begin{abstract}
(1)Embrapa Agrobiologia, BR 465, Km 7, CEP 23890-000 Seropédica, RJ. E-mail: gustavo@cnpab.embrapa.br, norma@cnpab.embrapa.br (2)Universidade Estadual da Bahia, Av. Edgard Chastinet, s/no, CEP 48900-000 Juazeiro, BA. E-mail: mirialind@yahoo.com.br (3)Embrapa MeioNorte, Av. Duque de Caxias, o 5650, Buenos Aires, CEP 64006-220 Teresina, PI. E-mail: freire@cpamn.embrapa.br
\end{abstract}

\begin{abstract}
Resumo - O conhecimento da variabilidade genética e da relação entre diferentes acessos de caupi é importante para maximizar o uso dos recursos genéticos disponíveis. Esse trabalho teve como objetivo avaliar a variabilidade genética em 45 acessos de caupi (Vigna unguiculata (L.) Walp.) oriundos do Brasil, EUA e Nigéria, por meio de marcadores RAPD. Foram encontrados 8 iniciadores polimórficos e um total de 48 bandas informativas. De acordo com os perfis polimórficos obtidos, foi observada a formação de quatro grupos genotípicos. Houve uma tendência de agrupamento em razão da origem dos acessos. A maioria dos acessos de variedades locais brasileiras pertence apenas a um grupo, o que sugere uma limitação da base genética. Vale ressaltar que nesse grupo não estavam presentes acessos da Nigéria considerados portadores de características agronômicas superiores, como, por exemplo, alta produtividade. RAPD é uma ferramenta eficiente, capaz de auxiliar a seleção de genótipos de caupi adaptados às diferentes condições edafo-climáticas brasileiras, com vistas ao aumento da produtividade e melhoria de outras características que atendam aos interesses regionais específicos.
\end{abstract}

Termos para indexação: Vigna unguiculata, marcador molecular, polimorfismo genético, variedade local, análise de agrupamento.

\section{Cowpea genetic variability analyzed by RAPD markers}

\begin{abstract}
The knowledge on genetic variability and the relationship among different cowpea accesses is important to maximize resource use represented by available cowpea genotypes. The objective of this work was to determine the genetic variability among 45 cowpea (Vigna unguiculata (L.) Walp.) accesses from Brazil, USA and Niger, characterized by RAPD (Random Amplified Polymorphic DNA) markers. Eight polymorphic primers were identified, comprehending a total of 48 informative bands. Based on the obtained polymorphic profiles, four major clusters were formed. Clustering was mainly influenced by the genotype origin. Most accesses from Brazilian landraces belong to just one cluster, suggesting a limited genetic basis. It is worth noting that none of the genotypes from Niger considered as possessing superior agronomical traits, such as high productivity, was present in this cluster. RAPD shows to be an efficient tool, capable of assisting cowpea genotype selection adapted to Brazilian edaphoclimatic conditions, aiming at increasing productivity and improving other desirable characteristics to meet the needs of specific regional demands.
\end{abstract}

Index terms: Vigna unguiculata, molecular marker, genetic polymorphism, Brazilian landrace, clustering analysis.

\section{Introdução}

O caupi (Vigna unguiculata (L.) Walp.) é uma leguminosa bastante cultivada por pequenos e médios produtores das regiões Nordeste e Norte do Brasil, e mais recentemente por grandes agricultores dessas regiões. No cenário mundial, o caupi tem grande importância econômica e social, especialmente na Índia e continente africano. Devido a sua rusticidade, a espécie exibe reconhecida capacidade de adaptação frente a estresses hídrico, térmico e salino. Além disso, pode ser utilizada como adubo verde, por apresentar eficiente produção de biomassa. Por essas características e também pelo alto teor de proteína presente nos grãos, o caupi pode ser considerado estratégico para a agricultura brasileira, principalmente por ocupar áreas marginais do Sertão Nordestino (Freire Filho et al., 2004).

Observa-se no caupi uma grande variabilidade fenotípica (Bezerra, 1997), o que tem permitido a seleção de genótipos adaptados a condições climáticas específicas e adequados à culinária regional. 
A introdução de técnicas de genética molecular, no início da década de 80, permitiu que os estudos de identificação, caracterização e mapeamento genético passassem a ser realizados com maior segurança, rapidez e eficiência, possibilitando inclusive a avaliação da variabilidade genética entre os acessos. A descoberta de novas gerações de marcadores moleculares, baseados na seqüência do DNA, tem possibilitado maior detecção de polimorfismo, em comparação com marcadores morfológicos ou baseados na análise de proteínas.

RAPD (DNA polimórfico amplificado ao acaso) é uma técnica molecular rápida, barata e informativa (Williams et al., 1990), pois dispensa o conhecimento prévio da seqüência de DNA alvo e amplifica as seqüências de DNA a partir de um par de iniciadores de seqüência arbitrária. Apesar disso, poucos trabalhos foram realizados com caupi empregando-se marcadores RAPD; entre eles, foi determinada a capacidade discriminatória de cultivares de $V$. angularis e Phaseolus vulgaris (Kaga et al., 1993), realizada a comparação por análise genômica de espécies de Vigna (Menancio-Hautea et al., 1993), a identificação da evidência de evolução ortóloga com soja (Maugham et al., 1996), a construção de um mapa genético de ligação (Kaga et al., 1996; Menéndez et al., 1997; Ubi et al., 2000) e determinada a diversidade entre os acessos de caupi de diferentes regiões (Mignouma et al., 1998).

Este trabalho teve como objetivo determinar a variabilidade genética entre acessos da Nigéria, EUA e Brasil, incluindo variedades locais brasileiras, por meio de marcadores de RAPD, visando à formação de grupos baseados em similaridade genética.

\section{Material e Métodos}

Foram utilizados 45 acessos de caupi oriundos do banco de germoplasma da Embrapa Meio-Norte, Teresina, PI (Tabela 1).

A extração de DNA de folhas jovens foi realizada de acordo com o protocolo descrito por Ferreira \& Grattapaglia (1998), utilizando-se, de cada planta, três discos de tecido foliar do primeiro trifólio com cerca de $1 \mathrm{~cm}$ de diâmetro cada, correspondendo a aproximadamente $100 \mathrm{mg}$.

Para a análise de marcadores RAPD foram testadas, na reação de amplificação, diferentes concentrações de DNA genômico purificado (10 ng, 20 ng e 30 ng), de enzima Taq DNA polimerase Promega (0,5, 1,0 e
1,5 unidade), de $\mathrm{MgCl}_{2}$ (1,5 mM, 2,0 mM, 2,5 mMe3,0 mM), e de cada um dos 20 iniciadores do kit E (Operon Technology) $(0,2 \mu \mathrm{M}$ e 0,4 $\mu \mathrm{M})$. Ainda completaram a reação de $25 \mu \mathrm{L}$, os reagentes dNTP $(100 \mathrm{mM})$ e TRIS (100 mM, pH 8,5). Foram realizados 45 ciclos para amplificação das amostras; desnaturação a $94^{\circ} \mathrm{C}$ por um minuto, anelamento a $35^{\circ} \mathrm{C}$ por um minuto e a polimerização a $72^{\circ} \mathrm{C}$ por dois minutos, seguida de uma etapa de extensão final à temperatura de $72^{\circ} \mathrm{C}$ por dez minutos.

Os produtos amplificados foram separados eletroforeticamente em gel de agarose $(1,4 \%)$ com tam-

Tabela 1. Acessos de caupi utilizados no estudo da variabilidade genética por meio de marcadores RAPD.

\begin{tabular}{|c|c|c|c|}
\hline Número & Nome & Origem & Coloração do grão \\
\hline 1 & VITA $7^{(2)}$ & Nigéria & Sempre-verde \\
\hline 2 & $\mathrm{CNC} 0434^{(2)}$ & Nigéria & Branca \\
\hline 3 & Tvu $249^{(1)}$ & Nigéria & Branca com olho preto \\
\hline 4 & Tvu $1489^{(1)}$ & Nigéria & Branca com olho preto \\
\hline 5 & Tvx $3038-05 D^{(1)}$ & Nigéria & Marrom \\
\hline 6 & Tvx $5058-09 \mathrm{C}-2^{(1)}$ & Nigéria & Branca com olho preto \\
\hline 7 & $\operatorname{Tvx} 1836-013 \mathrm{G}^{(1)}$ & Nigéria & Marrom \\
\hline 8 & IT $81 \mathrm{D}-1064^{(1)}$ & Nigéria & Vermelha \\
\hline 9 & IT $81 D-1069^{(1)}$ & Nigéria & Vermelha \\
\hline 10 & IT $81 \mathrm{D}-1073^{(1)}$ & Nigéria & Vermelha \\
\hline 11 & IT $82 \mathrm{G}-9^{(1)}$ & Nigéria & Preta \\
\hline 12 & IT $82 \mathrm{E}-49^{(1)}$ & Nigéria & Branca com olho preto \\
\hline 13 & IT $82 \mathrm{E}-32^{(1)}$ & Nigéria & Vermelha \\
\hline 14 & IT $82 \mathrm{D}-60^{(1)}$ & Nigéria & Branca com olho preto \\
\hline 15 & IT $82 \mathrm{D}-106 \mathrm{G}^{(1)}$ & Nigéria & Vermelha \\
\hline 16 & IT $82 \mathrm{D}-784^{(1)}$ & Nigéria & Marrom \\
\hline 17 & IT $82 \mathrm{D}-849^{(1)}$ & Nigéria & Marrom \\
\hline 18 & IT $82 \mathrm{D}-889^{(1)}$ & Nigéria & Vermelha \\
\hline 19 & IT $87 \mathrm{D}-611-3^{(1)}$ & Nigéria & Branca com olho marrom \\
\hline 20 & IT $87 \mathrm{D}-829-5^{(1)}$ & Nigéria & Branca com olho preto \\
\hline 21 & IT 87D-939-1 ${ }^{(1)}$ & Nigéria & Manchada (marrom e creme) \\
\hline 22 & IT $87 \mathrm{D}-1627^{(1)}$ & Nigéria & Branca com olho preto \\
\hline 23 & California $779^{(1)}$ & EUA & Branca com olho preto \\
\hline 24 & California $781^{(1)}$ & EUA & Manchada \\
\hline 25 & Pincess Ann ${ }^{(2)}$ & EUA & Manchada com olho preto \\
\hline 26 & AUBE Sister ${ }^{(2)}$ & EUA & Manchada com olho preto \\
\hline 27 & AU-94-MOB-10E- $8^{(1)}$ & EUA & Pintada vermelho e branco \\
\hline 28 & AR- $87-453^{(1)}$ & EUA & Branca com olho vermelho \\
\hline 29 & TE-93-242-10E- $8^{(1)}$ & Brasil & Marrom clara \\
\hline 30 & BR-12 Canindé(2) & Brasil & Marrom \\
\hline 31 & Macaíbo $^{(3)}$ & Brasil & Branca \\
\hline 32 & Lisão ${ }^{(3)}$ & Brasil & Marrom \\
\hline 33 & Canapu-RV-1 $1^{(3)}$ & Brasil & Marrom \\
\hline 34 & Canapu-RV-2 $2^{(3)}$ & Brasil & Marrom \\
\hline 35 & IPA $206^{(2)}$ & Brasil & Marrom \\
\hline 36 & EPACE $10^{(2)}$ & Brasil & Marrom \\
\hline 37 & Seridó ${ }^{(3)}$ & Brasil & Marrom \\
\hline 38 & Paulista $^{(3)}$ & Brasil & Marrom \\
\hline 39 & Paulistão ${ }^{(3)}$ & Brasil & Marrom \\
\hline 40 & TE-87-98-8 $\mathrm{G}^{(1)}$ & Brasil & Branca \\
\hline 41 & BR-14 Mulato ${ }^{(2)}$ & Brasil & Marrom \\
\hline 42 & Monteiro $^{(3)}$ & Brasil & Branca \\
\hline 43 & Aparecido $^{(3)}$ & Brasil & Branca \\
\hline 44 & Galanjão-CE ${ }^{(3)}$ & Brasil & Marrom \\
\hline 45 & BR-17 Gurgueia ${ }^{(2)}$ & Brasil & Sempre-verde \\
\hline
\end{tabular}

(1)Linhagem. ${ }^{(2)}$ Cultivar melhorada. ${ }^{(3)}$ Variedade local. 
pão TBE $(0,5 X)$. A corrida foi realizada a 80 volts, por cerca de 40 minutos, utilizando-se $15 \mu \mathrm{L}$ de cada amostra amplificada, adicionada a $5 \mu \mathrm{L}$ de corante blue/orange $1 \mathrm{X}$. Os géis corados com brometo de etídio (5 $\mathrm{mg} \mathrm{mL}^{-1}$ ) foram visualizados e fotografados em transiluminador, sobre luz ultra-violeta. O marcador $\phi X 174$ RF/Hae III, de 1.350 pb, foi utilizado.

Foi construída uma planilha de dados com informações referentes à presença e ausência de bandas, características de cada iniciador para cada um dos acessos. Em seguida, esses dados foram usados para construção de uma matriz de similaridade genética, com auxílio do programa NTSYS, desenvolvido por Rohlf (1994), onde foi utilizado o coeficiente de similaridade de Coincidência Simples (Simple Matching), que determina como similaridade tanto a presença como a ausência, de um caráter. A partir dessa matriz, o dendrograma foi obtido pelo método UPGMA (Método de média aritmética não ponderada).

\section{Resultados e Discussão}

Após a etapa de otimização, foram selecionadas as seguintes condições para a reação de amplificação: DNA genômico (20 ng), Taq DNA polimerase (1,0 unidade), $\mathrm{MgCl}_{2}(2,5 \mathrm{mM})$, e iniciadores $(0,2 \mu \mathrm{M}$ ou $0,4 \mu \mathrm{M})$. No caso de RAPD, a otimização das condições de amplificação, tais como as concentrações de $\mathrm{Mg}^{+2}$, DNA, Taq DNA polimerase e iniciadores, é um passo primordial e necessário antes de qualquer análise, uma vez que pequenas variações podem resultar em padrões de bandas diferentes (Kazan et al., 1993; Chen et al., 1997).

Dos 20 iniciadores testados, $40 \%$ apresentaram polimorfismo, enquanto dos restantes, três não foram capazes de gerar amplificação, em nenhuma das condições testadas, e os demais não foram informativos. As bandas foram mais nítidas quando se utilizou $0,2 \mu \mathrm{M}$ dos iniciadores OPE 07 e 18 e $0,4 \mu \mathrm{M}$ dos iniciadores OPE 01, 03, 04, 14, 19 e 20 (Figura 1).

Dwivedi et al. (2001) foram capazes de avaliar a diversidade genética de 26 acessos de amendoim, com oito iniciadores polimórficos. Os resultados mostraram a formação de cinco grupos genotípicos e indicaram que mesmo um número relativamente pequeno de iniciadores foi capaz de gerar informações sobre a variabilidade genética. Chen et al. (1997), ao avaliarem o polimorfismo em soja, encontraram 16 iniciadores polimórficos, a partir de 40 testados.
A amplificação com os oito iniciadores polimórficos gerou um total de 48 bandas, das quais 30 (62,5\%) foram polimórficas (Tabela 2). A amplitude de bandas polimórficas variou de $33 \%$ a $100 \%$, semelhante ao que foi observado por Jain et al. (1994). O número de bandas por iniciador variou entre três e nove, com tamanho entre 400 pb a 1.500 pb. Uma amplificação típica de RAPD produz, normalmente, entre duas e dez bandas visíveis na faixa de 400 pb a 2.000 pb (Bowditch et al., 1993; Mignouma et al., 1998).

O dendrograma mostrado na Figura 2 apresenta uma faixa de similaridade genética de $81 \%$ a $98 \%$ entre os acessos. Acima de $85 \%$ de similaridade, observa-se a formação de quatro grupos (I, II, III e IV), mostrando

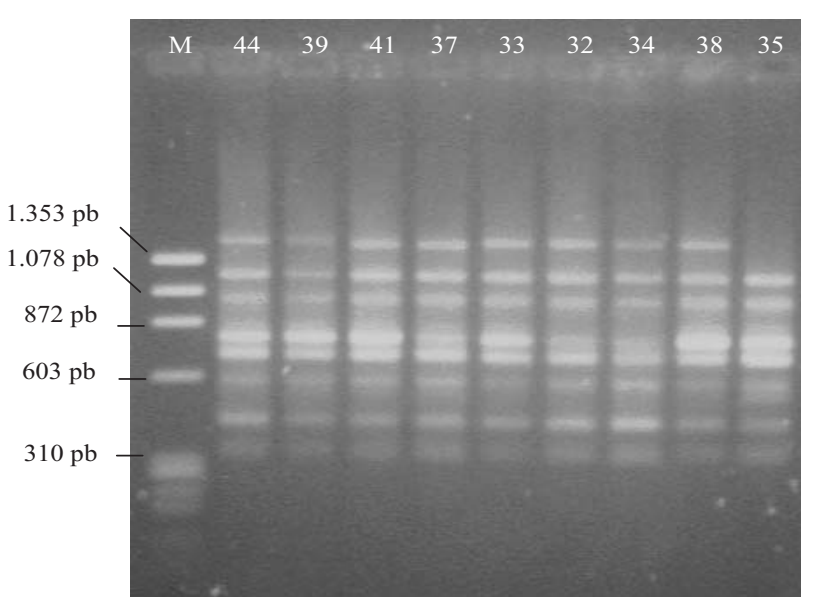

Figura 1. Eletroforese em gel de agarose, mostrando o polimorfismo de acessos de caupi, pela técnica de RAPD com o iniciador OPE 03. M corresponde ao marcador фX174RF/Hae III; os genótipos são Galanjão-CE (44), Paulistão (39), BR-14 Mulato (41), Seridó (37), Canapu-RV-1 (33), Lisão (32), Canapu-RV-2 (34), Paulista (38) e IPA 206 (35).

Tabela 2. Número e porcentagem de bandas polimórficas por iniciador (kit OPE) usado na caracterização da variabilidade genética dos acessos de caupi.

\begin{tabular}{cccc}
\hline Iniciador & $\begin{array}{c}\text { Bandas } \\
\text { geradas }\end{array}$ & $\begin{array}{c}\text { Bandas } \\
\text { polimórficas }\end{array}$ & $\begin{array}{c}\text { \% de bandas } \\
\text { polimórficas }\end{array}$ \\
\hline 1 & 3 & 3 & 100,0 \\
3 & 9 & 3 & 33,0 \\
4 & 6 & 3 & 50,0 \\
7 & 6 & 3 & 50,0 \\
14 & 6 & 4 & 66,0 \\
18 & 3 & 2 & 66,0 \\
19 & 7 & 6 & 85,0 \\
20 & 8 & 6 & 75,0 \\
\hline Total & 48 & 30 & 62,5 \\
\hline
\end{tabular}


uma tendência de agrupamento em função da origem dos acessos. Dentre os nove acessos contidos no grupo I, oito são de origem brasileira. No grupo II estão presentes quatro dos seis acessos provenientes dos EUA. O grupo III compreende 26 dos acessos estudados, o qual foi subdividido (III.1, III.2 e III.3) a 89\% de similaridade genética, ficando dois acessos fora dos subgrupos. No subgrupo III.3 foram observados 13 acessos da Nigéria, enquanto o grupo IV apresentava somente dois acessos da Nigéria.
Todos os acessos avaliados apresentaram uma similaridade acima de $80 \%$, mesmo quando oriundos de diferentes áreas geográficas (Brasil, Nigéria e EUA). Resultados similares foram encontrados para isoenzimas e proteínas de caupi (Panella \& Gepts, 1992; Vaillancourt et al., 1993). É possível que esses valores elevados resultem do processo de domesticação, que contribuiu para o estreitamento genético, podendo ser ainda mais pronunciado pela fixação de características de fácil detecção,

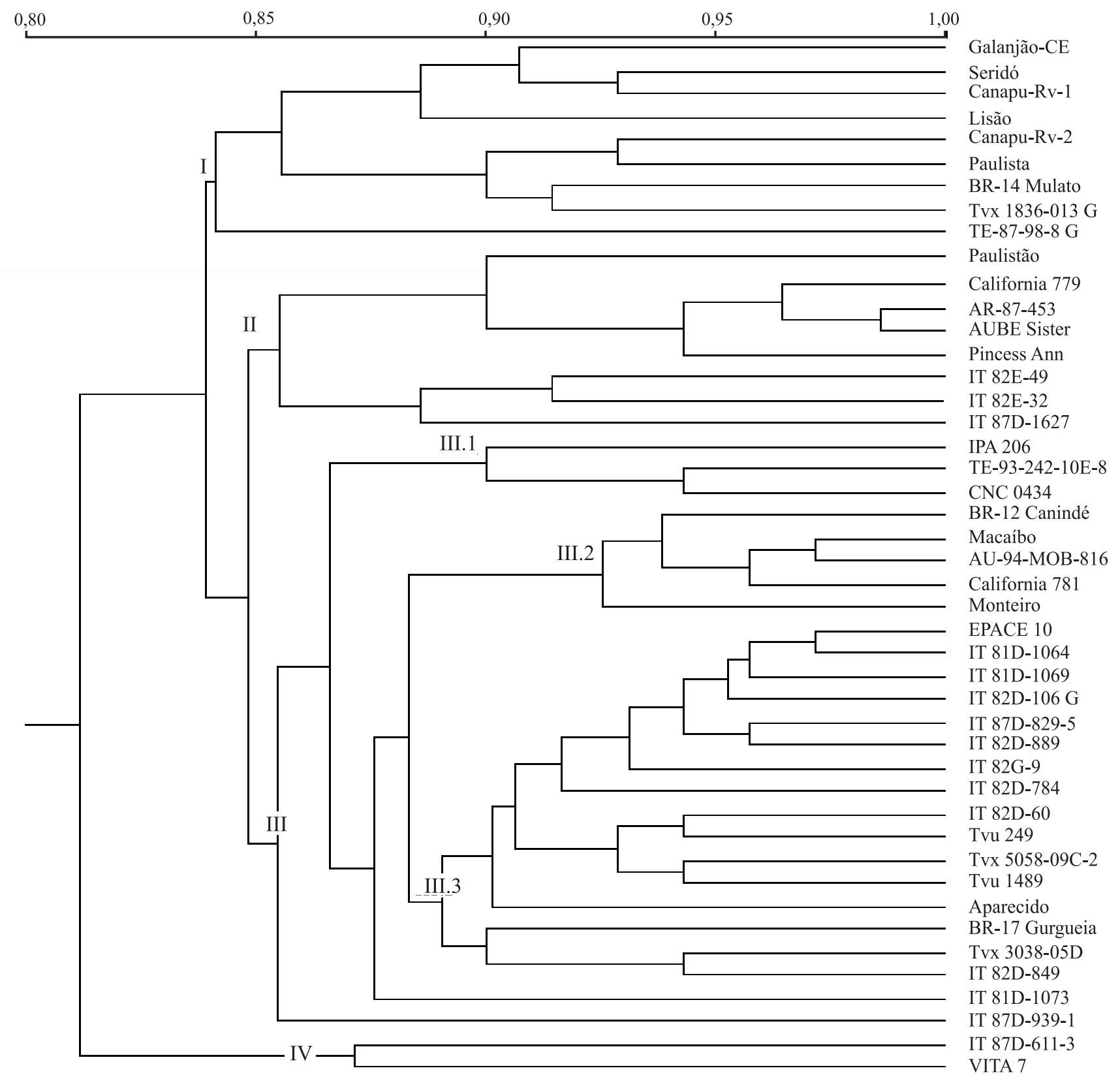

Figura 2. Dendrograma indicando a similaridade genética, a partir de RAPD, entre 45 acessos de caupi. 
como a cor e tamanho da semente, porte da planta, tipo de vagens (Vaillancourt et al., 1993) e também, a autofecundação (Kazan et al., 1993).

Sonnante et al. (1997), ao analisarem V. marina por RAPD e por isoenzimas, também observaram agrupamento de acordo com a origem dos grãos. Fofana et al. (1997), ao avaliarem a diversidade genética de $P$. lunatus, com 12 iniciadores, observaram agrupamento com base nas regiões andina e mesoamericana. Dentro de cada grupo formado, houve, ainda, divisão entre forma selvagem e cultivada.

Acredita-se que o caupi seja originário da África, tendo sido observados os maiores níveis de diversidade em países da África Ocidental, tais como a Nigéria (Ng, 1995). No presente trabalho, encontraram-se acessos da Nigéria nos quatro grupos obtidos por RAPD. A maior parte das variedades locais estudadas Galanjão-CE, Seridó, Canapu-RV-1, Lisão, Canapu-RV-2, Paulista e Paulistão - encontram-se no grupo I, o que sugere uma origem estreita do germoplasma em uso no Brasil. Resultados similares foram obtidos com acessos exóticos e cultivares da Índia (Jain et al., 1994), em que os exóticos apresentaram maior polimorfismo, formando um grupo isolado.

Bezerra (1997), ao estudar acessos de caupi, identificou grupos que apresentaram produtividade acima de $2.500 \mathrm{~kg} \mathrm{ha}^{-1}$. Comparando-se os resultados obtidos com os desse autor, observa-se que os acessos promissores (IT 81D-1064, IT 81D-1069, IT 82D-106 G, IT 82D-889) encontram-se no grupo III.3. Esses dados sugerem que além da base estreita da maioria das variedades locais brasileiras estudadas, sua semelhança com o acesso Tvx 1836-013 G, que apresenta cerca de $1.800 \mathrm{~kg} \mathrm{ha}^{-1}$, pode resultar em níveis baixos de produtividade. No entanto, é possível que esses materiais tenham sido os que melhor se adaptaram às condições locais no Brasil.

Além do agrupamento em função da origem dos acessos, observa-se também o agrupamento de acordo com a cor dos grãos. As variedades locais brasileiras do grupo I, apresentaram grãos marrons, enquanto os acessos com maior produtividade apresentaram cor vermelha (IT 81D-1064, IT 81D-1069 e IT 82D-106 G) ou cor branca (IT 82D-784, IT 82D-60, Tvu 249, Tvx 505809C-2 e Tvu 1489).

Outros estudos mostram como a diversidade genética, revelada por RAPD, relaciona-se com características morfológicas, agronômicas e bioquímicas (Koening
\& Gepts, 1989; Singh et al., 1991). Contrariamente, Mignouma et al. (1998) observaram que acessos de caupi com coloração do tegumento da semente similar, revelaram perfis distintos quando analisados por RAPD.

Dos 45 acessos utilizados neste trabalho, 28 foram estudados por Bezerra (1997), que utilizando características morfológicas e agronômicas, verificou a formação de dez grupos. Ao relacionar os resultados obtidos por esse autor com os revelados por RAPD, deste estudo, quatro (IT 81D-1064, IT 81D-1069, IT 82D-106 G, IT 82D-889) dos seis acessos, presentes no sub-grupo III.3, podem ser considerados promissores para cruzamentos futuros, por apresentarem características agronômicas desejáveis como porte ereto, alto grau de precocidade e elevado potencial de produção, apesar desses materiais não estarem adaptados às condições edafoclimáticas brasileiras.

Por meio da técnica RAPD, são identificadas bandas discriminantes que podem configurar-se como marcadores moleculares. A Figura 3 mostra que algumas bandas são comuns à maioria dos acessos, independentemente da origem, enquanto outras permitem

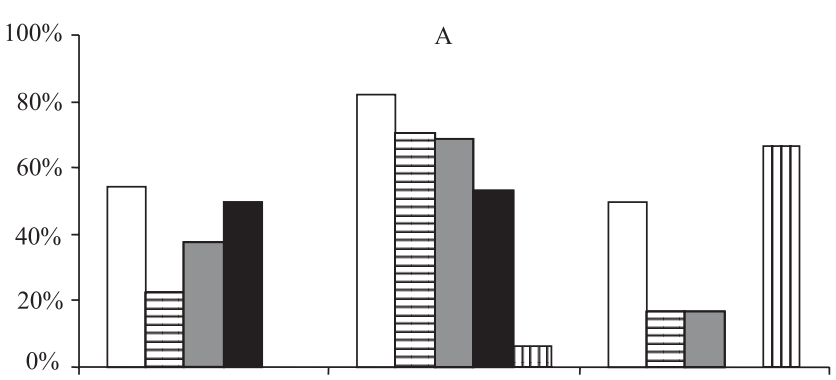

B

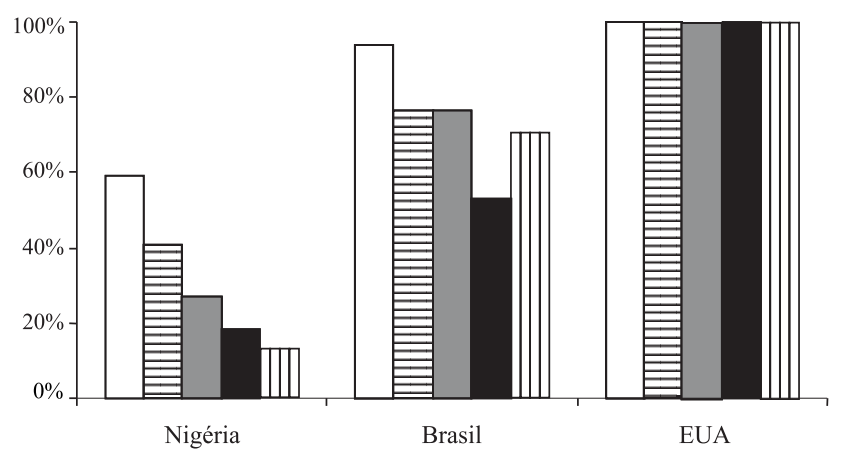

Figura 3. Identificação de marcador molecular RAPD, de acordo com a origem dos acessos de caupi. As letras referem-se às bandas diferenciais e os números aos iniciadores utilizados do kit $\mathrm{E}$ Operon. $\mathrm{A}: \square \mathrm{A} / 14$, 目 $\mathrm{B} / 1, \square \mathrm{C} / 19, \square \mathrm{A} / 7 \mathrm{e}$ 盂 $\mathrm{E} / 19$. B: $\square \mathrm{C} / 7$, 目B/18, $\square \mathrm{A} / 20, \mathbf{C} / 20$ e $\mathbb{m} \mathrm{G} / 20$. 
diferenciar os acessos de acordo com a origem. Apesar do baixo número de acessos dos EUA, a banda E do iniciador 19 (E/19) estava presente apenas nos acessos americanos. Já a banda A do iniciador 7 (A/7) não foi observada nos acessos dos EUA, estando presente em cerca de 50\% dos acessos da Nigéria e do Brasil. No entanto, a identificação de marcadores moleculares exige um volume significativo de dados, por isso são necessários mais estudos.

A crescente participação do caupi no cenário global exige novos investimentos, tanto do ponto de vista de melhoramento, como da introdução de novas tecnologias. Os dados revelados pela análise de RAPD, associados aos conhecimentos de genética quantitativa, fornecem subsídios para a criação e o desenvolvimento de novos acessos. Assim, o potencial genético da espécie poderá ser otimizado a partir da variabilidade genética disponível, produzindo-se genótipos adaptados a diferentes regiões e ecossistemas brasileiros.

\section{Conclusões}

1. O uso da técnica RAPD permite determinar a variabilidade genética de acessos de caupi provenientes do Brasil, Nigéria e EUA.

2. De acordo com o perfil polimórfico dos acessos de caupi, foi observada a formação de quatro grupos genotípicos.

3. A maioria dos acessos de variedades locais brasileiras agrupam-se em apenas um grupo, o que sugere uma limitação da base genética.

4. Há uma tendência de agrupamento em função da origem dos acessos.

\section{Agradecimentos}

Ao CNPq e Prodetab, pelo financiamento dos trabalhos.

\section{Referências}

BEZERRA, A.A.C. Variabilidade e diversidade genética em caupi (Vigna unguiculata (L.) Walp.) precoce, de crescimento determinado e porte ereto e semi-ereto. 1997. 105p. Dissertação (Mestrado) - Universidade Federal Rural de Pernambuco, PE.

BOWDITCH, B.M.; ALBRIGHT, D.G.; WILLIAMS, J.G.K.; BRAUN, M.J. Use of randomly amplified polymorphic DNA markers in comparative genome studies. Methods in Enzymology, v.224, p.294-309, 1993.

CHEN, L.F.O.; KUO, H.Y.; CHEN, M.H.; LAI, K.N.; CHEN, S.C.G. Reproducibility of the differential amplification between leaf and root DNA in soybean revealed by RAPD markers. Theoretical and Applied Genetics, v.95, p.1033-1043, 1997.

DWIVEDI, S.L.; GURTU, S.; CHANDRA, S.; YUEJIN, W.; NIGAM, S.N. Assessment of genetic diversity among selected groundnut germplasm: 1- RAPD analysis. Plant Breeding, v.120, p.345-359, 2001.

FERREIRA, M.E.; GRATTAPAGLIA, D. Introdução ao uso de marcadores moleculares em análise genética. 3.ed. Brasília: Embrapa-Cenargen, 1998. 220p. (Embrapa-Cenargen. Documentos, 20).

FREIRE FILHO, F.R.; LIMA, J.A.A.; VIANA, F.M.P.; RIBEIRO, V.Q. Feijão caupi: avanços tecnológicos. Teresina: Embrapa MeioNorte, 2004. 640p.

FOFANA, B.; VEKEMANS, X.; JARDIN, P. du; BAUDOIN, J.P. Genetic diversity in Lima bean (Phaseolus lunatus L.) as revealed by RAPD markers. Euphytica, v.95, p.57-165, 1997.

JAIN, A.; BHATIA, S.; BANGA, S.S.; PRAKASH, S.; LAKSHMIKUMARAN, M. Potential use of random amplified polymorphic DNA (RAPD) technique to study the genetic diversity in Indian mustard (Brassica juncea) and its relationship to heterosis. Theoretical and Applied Genetics, v.88, p.116-122, 1994.

KAGA, A.; OHNISHI, M.; ISHII, T.; KAMIJIMA, O.O. A genetic linkage map of azuki bean constructed with molecular and morphological markers using an interspecific population (Vigna angularis x V. nakashimae). Theoretical and Applied Genetics, v.93, p.658-663, 1996.

KAGA, A.; HOSAKA, K.; KIMURA, T.; MISOO, S.; KAMIJIMA, O.O. Application of random amplified polymorphic DNA (RAPD) analysis for azuki bean and its related genera. Science Reports of Faculty of Agriculture, v.20, p.171-176, 1993.

KAZAN, K.; MANNERS, J.M.; CAMERON, D.F. Genetic variation in agronomically important species of Stylosanthes determined using random amplified polymorphic DNA markers. Theoretical and Applied Genetics, v.85, p.882-888, 1993.

KOENING, R.; GEPTS, P. Allozyme diversity in wild Phaseolus vulgaris: further evidence for two major centers of genetic diversity. Theoretical and Applied Genetics, v.78, p.809-817, 1989.

MAUGHAM, P.J.; MARROF, M.A.S.; BUSS, G.R. Molecularmarker analysis of seed-weight: genomic locations, gene action, and evidence for orthologous evolution among three legume species. Theoretical and Applied Genetics, v.93, p.574-579, 1996.

MENANCIO-HAUTEA, D.; FATOKUN, C.A.; KUMAR, L.; DANESH, D.; YOUNG, N.D. Comparative genome analysis of mungbean (Vigna radiata (L.) Wilczek) and cowpea (V. unguiculata (L.) Walpers) using RFLP mapping data. Theoretical and Applied Genetics, v.86, p.797-810, 1993.

MENÉNDEZ, C.M.; HALL, A.E.; GEPTS, P. A genetic linkage map of cowpea (Vigna unguiculata) developed from a cross between two inbred, domesticated lines. Theoretical and Applied Genetics, v.95, p.1210-1217, 1997.

MIGNOUMA, H.D.; NG, N.Q.; IKEA, J.; THOTTAPILLY, G. Genetic diversity in cowpea as revealed by random amplified polymorphic DNA. Journal of Genetics \& Breeding, v.53, p.151159, 1998. 
NG, N.Q. Cowpea (Vigna unguiculata). In: SMART, J.; SIMMONDS, S. (Ed.). Evolution of crops plants. 2.ed. London: Longman, 1995. p.326-332.

PANELLA, L.; GEPTS, P. Genetic relationship within Vigna unguiculata (L.) Walp. based on isozymes analyses. Genetic Resources and Crop Evolution, v.39, p.71-88, 1992.

ROHLF, F.J. NTSYS-pc: numerical taxonomy and multivariate analysis system, version 1.80. New York: Exeter Software, 1994.

SINGH, S.P.; GUTIÉRREZ, J.A.; MOLINA, A.; URREA, C.; GEPTS, P. Genetic diversity in cultivated common bean: 2- Markerbased analysis of morphologic and agronomic traits. Crop Science, v.31, p.23-29, 1991.

SONNANTE, G.; SPINOSA, A.; MARANGI, A.; PIGNONE, D. Isozymes and RAPD analysis of the genetic diversity within and between Vigna luteola and V. marina. Annals of Botany, v.80, p.741746, 1997.

UBI, B.E.; MIGNOUMA, H.; THOTTAPPILY, G. Construction of a genetic linkage map and QTL analysis using a recombinant inbred population derived from an intersubspecific cross of cowpea (Vigna unguiculata (L.) Walp.). Breeding Science, v.50, p.161172, 2000

VAILLANCOURT, R.E.; WEEDEN, N.F.; BARNARD, J. Isozyme diversity in the cowpea species complex. Crop Science, v.33, p.606613, 1993.

WILLIAMS, J.G.K.; KUBELIK, A.R.; LIVAK, K.J.; RAFALSKI, J.A.; TINGEY, S.A. DNA polymorphism amplified by arbitrary primers are useful as genetic markers. Nucleic Acids Research, v.18, p.6531-6535, 1990.

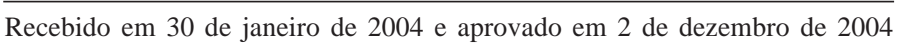

